J. Dairy Sci. 99:1747-1754

http://dx.doi.org/10.3168/jds.2015-10516

(C) 2016, THE AUTHORS. Published by FASS and Elsevier Inc. on behalf

of the American Dairy Science Association ${ }^{\circledR}$. This is an open access article under

the CC BY-NC-ND license (http://creativecommons.org/licenses/by-nc-nd/3.0/).

\title{
Short communication: Influence of labeling on Australian and Chinese consumers' liking of milk with short (pasteurized) and long (UHT) shelf life
}

\author{
D. G. Liem, ${ }^{* 1}$ D. P. Bolhuis,${ }^{*}$ X. Hu, ${ }^{\dagger} \dagger$ and R. S. J. Keast ${ }^{*}$ \\ *Centre for Advanced Sensory Science (CASS), Deakin University, Burwood, Australia 3125 \\ †College of Food Science and Technology, Huazhong Agricultural University, Wuhan, China 430070
}

\begin{abstract}
Sixty percent of milk consumed in China has a long shelf life (UHT), presumably because milk with a short shelf life (pasteurized) is comparatively expensive. This in contrast to Australia, where $10 \%$ of consumed milk is UHT and the price between UHT and pasteurized milk is equivalent. Whether UHT is actually more liked than pasteurized milk by Chinese consumers is unknown. However, the potential positive halo around the expensive pasteurized milk might result in Chinese consumers liking milk more when it is labeled as "short shelf-life milk." To test these hypotheses, Chinese ( $\mathrm{n}=$ 48, 20 males, 28 females, $23 \pm 7.2$ yr) and Australian ( $\mathrm{n}=93,11$ males, 82 females, $24 \pm 5.6 \mathrm{yr})$ consumers tasted and rated (9-point hedonic scale), in a randomized order, $3 \times 30$-mL samples of UHT milk (labeled as "long shelf-life milk," "short shelf-life milk," or "milk") and $3 \times 30-\mathrm{mL}$ samples of pasteurized milk (also labeled as "long shelf-life milk," "short shelf-life milk," or "milk"). Australian participants' liking of milk was not influenced by labeling. Regardless of what the label stated, they always preferred the taste of pasteurized milk over the taste of UHT milk. This was different for Chinese participants, who preferred the taste of UHT milk over the taste of pasteurized milk, but in general had a higher liking for any milk that was labeled "short shelf-life milk." Both Australian and Chinese were more positive about pasteurized than UHT milk. In conclusion, Chinese, but not Australian, consumers' liking of milk was guided by the positive expectations of pasteurized milk and the negative expectations of UHT milk. Further research is needed to investigate if the present findings can be extrapolated to a larger and more varied group of Chinese and Australian consumers.
\end{abstract}

Received October 12, 2015.

Accepted December 3, 2015.

${ }^{1}$ Corresponding author: Gie.liem@deakin.edu.au
Key words: consumer, sensory, cross-cultural, milk, liking

\section{Short Communication}

"I have a dream that every Chinese, especially children, could have half a kilogram of dairy product every day"; these words, spoken by the Chinese Premier in 2006 after visiting a dairy farm, illustrate China's growing appetite for bovine milk (hereafter referred to as milk). The Chinese milk market has grown by an estimate of $42 \%$ from 2006 to 2010 (International Market Bureau, 2012) and although local dairy farmers are emerging (Huang et al., 2012), they are struggling with the increasing demand for milk (Hongfeng, 2011; Dong et al., 2015). In addition, due to dairy-related food scares such as the melamine scandal in 2008, there is a lack of trust in Chinese dairy (Qiao et al., 2010; Xiu and Klein, 2010; Dong and Li, 2015) and a positive attitude toward imported milk. It is therefore not surprising that milk producers in Asia Pacific countries such as Australia and New Zealand are eager to enter the Chinese milk market (Tay, 2014).

The Chinese milk market is, however, different from the market in Australia. In China, an estimated $60 \%$ of the ready-to-drink (unflavored white) milk is long shelflife milk and is produced by UHT treatment (Weston, 2014). Although UHT milk comes in various flavors such as chocolate and strawberry, to compare UHT with pasteurized milk, the present paper will focus only on unflavored UHT milk. Ultra-high-temperature milk is heated to 138 to $150^{\circ} \mathrm{C}$ for 1 or $2 \mathrm{~s}$, after which it is packed in sterile containers. This results in an ambient stable product that, unless opened, has a shelf life from 6 mo to 1 yr (Sumonsiri and Barringer, 2014). This in contrast to pasteurized milk, which is heated to $72^{\circ} \mathrm{C}$ for $15 \mathrm{~s}$. Pasteurized milk is not sterile and therefore needs to be stored at $<4.4^{\circ} \mathrm{C}$ at all times and has a shelf life of approximately 2 wk (Sumonsiri and Barringer, 2014). In Australia, about 10\% of ready-to-drink milk 
consumed is produced by UHT and the remainder is pasteurized (Dairy Australia, 2014).

The flavor profile of UHT milk is noticeably different from that of pasteurized milk; UHT milk has been described as having "cooked" and "flat" flavors, partly due to the increase of various sulfur-containing compounds, methyl ketones, and aliphatic aldehydes (Zabbia et al., 2012). In addition, the Maillard reaction, which is induced by the UHT process, increases various flavor compounds that give UHT milk its distinct "off-flavors" (Hashim and Chaveron, 1998; Singh et al., 2009; Zabbia et al., 2012). The presence of these offflavors has been associated with consumer rejection of UHT milk in countries where consumers mainly drink pasteurized milk (Hough et al., 2004; Zabbia et al., 2012). Despite this difference in taste, UHT milk contains approximately the same amount of calories, milk fat, protein, fat-soluble vitamins, and minerals such as calcium, potassium, and phosphorus (Dunkley and Stevenson, 1987) as pasteurized milk. Some micronutrients such vitamin $\mathrm{B}_{12}$ and $\mathrm{B}_{6}$, however, might be lost or decreased during the UHT process and storage of UHT milk (Dunkley and Stevenson, 1987; Barraquio, 2014).

Consumers in China (International Market Bureau, 2012) and Australia (Perkins and Deeth, 2001) may perceive UHT as a low-quality product due to its taste, long shelf life, and ambient-stable nature. In addition, Chinese consumers might be overly positive about imported Australian pasteurized milk because of the presumed quality and the extremely high price (approximately A $\$ 8 / \mathrm{L}$ ) Chinese consumers pay for imported Australian pasteurized milk in China (Thomson, 2014).

Consumer quality perception consists of a range of variables including taste, healthfulness, and safety (Grunert, 2005; Keast and Lau, 2006). It is important to make a distinction between the "expected quality" based on information given to consumers before they actually taste the product, and "experienced quality"; for example, the perceived taste and the experienced health benefits. Several studies suggest that expected quality, as cued by, for example, price (Plassmann et al., 2008), country or area of origin (Wansink et al., 2007; Williamson et al., 2012; Tang et al., 2015) and ingredient claims, such as "contains soy" (Wansink and Park, 2002) and "reduced in salt" (Liem et al., 2012a,b) can influence experienced quality (for review, see Piqueras-Fiszman and Spence, 2015).

The aim of the present research was to determine the influence of process information (UHT vs. pasteurized milk) and country of origin (China vs. Australia) on Chinese and Australian consumers' expected quality and perceived liking of milk.

To investigate this aim, participants tasted and rated their liking of white unflavored UHT and pasteurized milk with either a "long shelf life milk" (hereafter referred to as long SL), or a "short shelf life milk" (hereafter referred to as short SL) label. The wording of labels was chosen in such way to make it easier for participants to understand, because some might not be familiar with the terms "UHT" and "pasteurized" (Hongfeng, 2011). After the taste testing, participants completed a questionnaire about their expectations of different types of milk. Demographic information was also collected, including sex and age. Liking of milk samples was conducted in computerized, partitioned sensory booths in the Centre for Advanced Sensory Science at Deakin University (Burwood, Australia), and data were collected using Compusense Five software (version 5.2; Compusense Inc., Guelph, ON, Canada). The study design and protocol was approved by the Deakin University Human Ethics Committee (HREC 2012-162); all subjects provided informed, written consent before study commencement. The subjects were asked to refrain from eating, drinking (except room temperature water), brushing teeth, or chewing gum for $1 \mathrm{~h}$ before testing.

The milk samples $(30 \mathrm{~mL}$ ) were pasteurized (Coles Supermarkets Pty Ltd., Australia) and UHT (Coles Supermarkets Pty Ltd.), both 4\% (wt/vol) fat, served in clear plastic medicine cups at $5^{\circ} \mathrm{C}$. The pasteurized and UHT milks were presented 6 times in a randomized order. Each time the milks had different labels (i.e., "short shelf-life milk," "long shelf-life milk," or "milk").

All Chinese (mainland China and Hong Kong; $\mathrm{n}=$ 48, 20 males, 28 females, $23 \pm 7.2$ yr) and Australian $(\mathrm{n}=93,11$ males, 82 females, $24 \pm 5.6 \mathrm{yr}$ ) participants were students enrolled in an undergraduate degree at Deakin University who consumed milk at least once per week. The Chinese participants had lived in Melbourne at the time of testing for, on average, $2.3 \pm 1.6 \mathrm{yr}$ but had spent, on average, $88 \pm 6.0 \%$ of their lives in China.

The researcher gave participants the following instruction: "You will be given different types of milk. Some of these milks are called short shelf life milks. This milk always needs to be refrigerated and usually stays good for about a week or two. Other milks are called long shelf life milks; this milk does not need to be refrigerated as long as it is not opened. Usually this milk stays good for about half a year to a year." First, participants were instructed to rinse their mouth with water. Next, they were provided with their first cup of milk. On a piece of paper, participants read which milk they were tasting. For example, "This is long shelf life milk. Please taste this long shelf life milk and rate how much you like it."

Participants were instructed to pay close attention to which milk they were tasting. Then, they tasted and 
rated the milk on a 9-point hedonic scale $(1=$ dislike extremely, $2=$ dislike very much, $3=$ dislike moderately, $4=$ dislike slightly, $5=$ neither like nor dislike, $6=$ like slightly, $7=$ like moderately, $8=$ like very much, 9 = like extremely). Milk was not swallowed. After participants rated the first milk, they rinsed their mouths with water and continued with the next milk until all 6 milks were tasted and rated.

Once participants completed the milk tasting, they completed a questionnaire about their milk usage habits (i.e., added to a drink, added to cereal, or on its own in a mug or glass), consumption patterns (i.e., daily, 3 to 6 times a week, 1 to 2 times a week, less than once a month, never), and type of milk they usually consumed (i.e., full-fat milk, reduced-fat milk, long shelf life milk, and short shelf life milk). In addition, participants were given a list of 17 attributes (see Table 3) and asked which attributes they associated with "short shelf life milk from China." Participants could select as many attributes as they wanted. This procedure was repeated for "short shelf life milk from Australia," "long shelf life milk from China" and "long shelf life milk from Australia." The selected attributes were based on previous sensory research with UHT milk (Hashim and Chaveron, 1998; Singh et al., 2009) and general sensory science (Meilgaard et al., 1999).

To measure how participants associated different types of milk with different aspects of quality, they were given a list of 4 product descriptors (i.e., "long shelf life milk," "short shelf life milk," "produced in China," "produced in Australia," "endorsed by Chinese consumers," and "endorsed by Australian consumers"). Participants were asked which of these product descriptions they would associate with the following milk descriptors: "good-tasting milk," "high-quality milk," "healthy milk," and "safe milk." They could choose as many product descriptors as they wanted for each of the milk descriptors.

Statistical analyses included a general linear univariate model with liking as the dependent variable, milk offered and labels as fixed factors; participant ID as random factor was applied to assess the main and interaction effects of "milk offered" and "labeling" on liking of milk. Independent $t$-tests with Bonferroni corrections were applied to test for significant differences in milk liking between Chinese and Australian participants.

To estimate participants' negative and positive expectations toward short and long SL milk from China and Australia, 9 attributes were grouped in positive and negative attributes (see Table 3 for exact grouping of attributes). The attributes sweet, sour, salty, carton, cooked, and oxidized were not included in the positive and negative grouping, because it was not clear whether the participants would judge these attributes as positive or negative.

Wilcoxon analyses with Bonferroni corrections were carried out to determine differences in expected quality between long and short SL milk, and between Chinese and Australian milk. The Mann-Whitney U-test was conducted to investigate differences in quality perception between Chinese and Australian participants. All statistical procedures were performed with IBM SPSS statistics (version 22, 64-bit edition; SPSS/IBM Corp., Armonk, NY).

The results suggest that the milk consumption habits of the Chinese and Australian participants were similar with the exception of how often participants drank milk on its own (Table 1). About $86 \%$ of the Chinese participants reported that they drank milk on its own at least once a week, whereas about $49 \%$ of the Australian participants reported that they never drank milk on its own $(P<0.001)$. Furthermore, $61 \%$ of the Chinese participants were more likely to consume full-fat milk, whereas only $16 \%$ of Australian participants usually consumed full-fat milk $(P<0.001)$.

Figure 1 shows consumers' liking responses of UHT and pasteurized milk. Australian participants' liking of milk was not influenced by labeling $(P=0.47)$. No matter what the label stated, they always preferred the taste of pasteurized milk over the taste of UHT milk ( $P$ $<0.001)$. This was different for Chinese participants, who preferred the taste of UHT milk over the taste of pasteurized milk $(P=0.01)$, but in general had a higher liking for any milk that was labeled as "short shelf life milk" ( $P=0.01)$. Both Australian and Chinese were more positive about pasteurized than UHT milk.

The UHT milk was liked more by Chinese than by Australian participants when the UHT milk was labeled as "milk" $(6.0 \pm 1.4$ vs. $5.1 \pm 1.9, P<0.01)$, or "short shelf life milk" $(6.2 \pm 1.6$ vs. $5.2 \pm 1.9 ; P<$ 0.01 ), but not when the UHT milk was labeled as "long shelf life milk" $(5.7 \pm 1.6$ vs. $5.5 \pm 1.8 ; P=0.2)$. When pasteurized milk was labeled as "long shelf life milk," Chinese participants liked it less than did the Australian participants $(5.1 \pm 1.6$ vs. $5.6 \pm 1.9 ; P<0.05)$. Such a difference was not observed when pasteurized milk was labeled as either "short shelf life milk" (5.9 \pm 1.8 vs. $5.9 \pm 1.8 ; P=0.7)$ or "milk" ( $5.6 \pm 1.8$ vs. 5.9 $\pm 1.7 ; P=0.1 ;$ Figure 1$)$.

Chinese participants associated more positive attributes to short SL milk from China (1.2 \pm 1.2 attributes) or Australia (2.7 \pm 1.1 attributes) than to long SL milk from China (0.6 \pm 0.9 attributes) or Australia (1.8 \pm 1.5) (all $P$-values $<0.01$ ). Short SL milk from China was associated with fewer positive attributes than short SL milk from Australia $(P<0.01)$. Long SL milk from 
Table 1. Milk consumption of Chinese and Australian participants

\begin{tabular}{|c|c|c|c|}
\hline Group & $\begin{array}{l}\text { Chinese } \\
(\mathrm{n}=48)\end{array}$ & $\begin{array}{c}\text { Australian } \\
(\mathrm{n}=98)\end{array}$ & $P$-value ${ }^{1}$ \\
\hline \multicolumn{4}{|c|}{ Type of milk usually consumed (\% of group) } \\
\hline Long shelf life (UHT) & 8.3 & 15.2 & \multirow[t]{3}{*}{0.38} \\
\hline Short shelf life (pasteurized) & 77.1 & 62.6 & \\
\hline Combination & 14.6 & 15.2 & \\
\hline \multicolumn{4}{|c|}{ Fat percent of milk usually consumed ( $\%$ of group) } \\
\hline Full-fat & 61.2 & 16.2 & \multirow[t]{4}{*}{$<0.001$} \\
\hline Low-fat & 26.5 & 35.4 & \\
\hline Skim & 10.2 & 27.3 & \\
\hline Combination or other & 2 & 19.2 & \\
\hline \multicolumn{4}{|c|}{ Milk added to a drink (i.e., milk or coffee; $\%$ of group) } \\
\hline Daily & 16.3 & 46.5 & \multirow[t]{6}{*}{$<0.01$} \\
\hline 3 to 6 times a week & 22.4 & 12.1 & \\
\hline 1 to 2 times a week & 34.7 & 19.2 & \\
\hline Less than once a month & 36.7 & 7.1 & \\
\hline Never & 10.2 & 12.1 & \\
\hline Other & 0 & 2 & \\
\hline \multicolumn{4}{|c|}{ Milk added to cereals of porridge ( $\%$ of group) } \\
\hline Daily & 8.2 & 19.2 & \multirow{6}{*}{0.06} \\
\hline 3 to 6 times a week & 24.5 & 23.2 & \\
\hline 1 to 2 times a week & 26.5 & 19.2 & \\
\hline Less than once a month & 28.6 & 15.2 & \\
\hline Never & 12.2 & 20.2 & \\
\hline Other & 0 & 2 & \\
\hline \multicolumn{4}{|c|}{ Milk on its own (i.e., from a glass or mug; $\%$ of group) } \\
\hline Daily & 18.4 & 5.1 & \multirow[t]{6}{*}{$<0.001$} \\
\hline 3 to 6 times a week & 28.6 & 9.1 & \\
\hline 1 to 2 times a week & 38.8 & 15.2 & \\
\hline Less than once a month & 10.2 & 19.2 & \\
\hline Never & 4.1 & 48.5 & \\
\hline Other & 0 & 2 & \\
\hline
\end{tabular}

${ }^{1}$ Difference in frequency distribution between Chinese and Australian participants.

China was associated with fewer positive $(0.6 \pm 0.9$ vs. $1.8 \pm 1.5$ attributes) and more negative attributes (1.2 \pm 1.1 vs. $0.4 \pm 0.7$ attributes) than long SL milk from Australia (all $P$-values $<0.001$; Table 2 and Table 3 )

Australian participants associated fewer positive attributes ( $0.4 \pm 0.8$ vs. $2.7 \pm 1.1$ attributes) but more negative attributes $(1.3 \pm 1.0$ vs. $0.3 \pm 0.6$ attributes $)$ to short SL milk from China than to short SL milk from Australia $(P<0.001)$. The same was observed for long SL milk (positive attributes: $0.3 \pm 0.7$ vs. $1.5 \pm$ 2.6; $P<0.001$; negative attributes: $1.4 \pm 1.2$ vs. $0.8 \pm$ 1.0). In addition, they assigned fewer positive but more negative attributes to long SL milk than to short SL milk (all $P$-values $<0.001$; Table 2 and Table 3 ).

Chinese participants tended to associate the word "unsafe" more often with long SL milk from China than to short SL milk from China $(P=0.06)$. This was not the case for milk from Australia $(P=1.0$; Table 2). Along the same lines, as shown in Table $4,45 \%$ of the participants associated the words "safe milk" with long SL milk and $61 \%$ of the participants associated these words with short SL milk. However, Chinese milk was always more often associated with the word "unsafe" than milk from Australia (short SL milk China vs. Australia, $P=0.05$; long SL milk China vs. Australia, $P<0.001$; Table 3). Similar results were obtained when Chinese consumers were asked which country of origin they associated with the words "safe milk." Only $12 \%$ associated "safe milk" with "produced in China," whereas more than $90 \%$ associated the words "safe milk" with "produced in Australia" $(P<0.001$; Table 4). Australian participants, however, did differentiate between short and long SL milk from China: short SL milk from China was more often associated with the word "unsafe" than long SL milk from China $(P<$ 0.001). This difference was not observed, however, for long and short SL milks from Australia $(P=1.0$; Table $3)$. When Australian consumers were asked which milk in general (long SL or short SL) they associated with the words "safe milk," they did not differentiate $(P=$ 0.78; Table 3).

Like the Chinese participants, Australian participants always associated the word "unsafe" more often with Chinese milk than with Australian milk (short SL milk China vs. Australia, $P<0.001$; long SL milk China vs. Australia, $P<0.001$; Table 3). This is in 

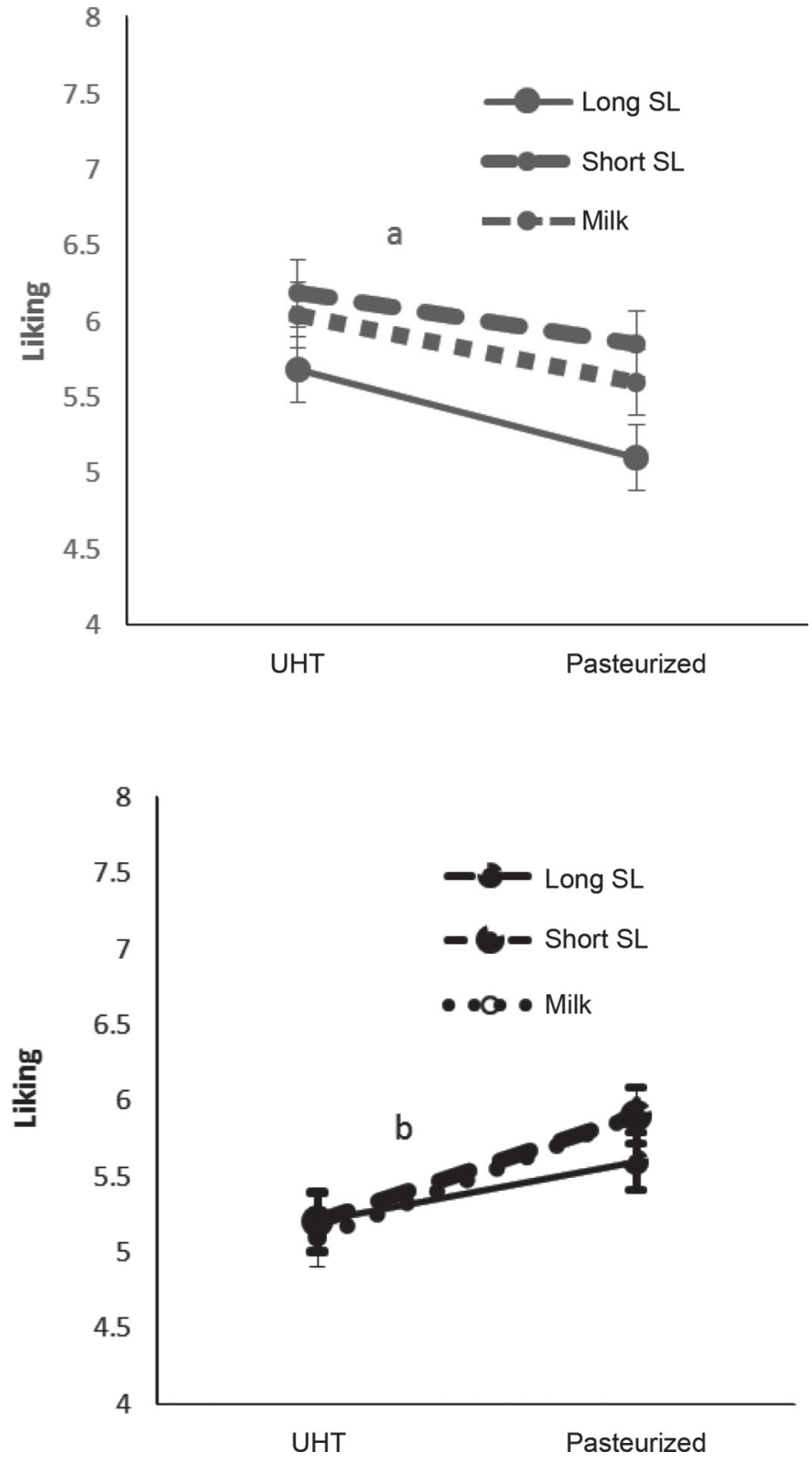

Figure 1. Liking (9-point hedonic scale, mean \pm SEM) of UHT and pasteurized milk when labeled as "long shelf life (SL) milk," "short SL milk," or "milk" for Chinese participants ( $=48$, upper panel) and Australian participants $\left(\mathrm{n}=93\right.$, lower panel). ${ }^{\text {aSignificant main effect }}$ of labels $(P<0.01)$. 'bignificant main effect of type of milk offered $(P<0.001)$.

line with data shown in Table 4, which suggests that only $5 \%$ of Australian participants associated the words "safe milk" with "produced in China," whereas $91 \%$ of Australian consumers associated the words "safe milk" with "produced in Australia" $(P<0.001$; Table 4).

Australian participants associated the words "endorsed by Australian consumers" more often with "good-tasting milk" and "high-quality milk" than Chinese participants $\left(\chi^{2}=9.3, P<0.01 ; \chi^{2}=7.4, P<\right.$ 0.01 , respectively). A significantly larger proportion of Australian than Chinese participants (29.3\% vs. $4.5 \%)$ associated long SL milk with "high-quality milk" $\left(\chi^{2}=\right.$ $4.4, P<0.05)$ and "healthy milk" $\left(25.3 \%\right.$ vs. $0 \%, \chi^{2}=$ 7.3, $P<0.05$; Table 3).

The results of this exploratory study revealed that both Chinese and Australian participants in our sample were more positive about pasteurized milk than about UHT milk, but only the Chinese participants' liking was significantly influenced by labeling. In a blind taste test (when UHT and pasteurized milk were labeled the same), Chinese participants liked the UHT milk more than the pasteurized milk. This suggests that it is not the taste of pasteurized milk that attracts Chinese consumers, but the presumption that the milk is pasteurized. It should be noted that this study investigated a specific group of Chinese consumers and whether the present results can be extrapolated to a more varied group of Chinese consumers remains to be investigated.

Chinese participants judged UHT milk as a lowquality product. The results suggest that the lowquality perception of UHT milk is associated with a low perceived healthfulness of UHT milk. Chinese participants were more negative about the healthfulness of UHT milk than were Australian consumers, which could be the reason why Chinese participants' liking of the offered milk was negatively influenced by the label "long shelf life milk." Previous studies suggested that pasteurized milk was seen as more healthy than

Table 2. Mean number of attributes $( \pm \mathrm{SD})$ expected to be related to short shelf life (short SL; pasteurized) and long shelf life (long SL; UHT) milk from China and Australia as judged by Chinese and Australian participants

\begin{tabular}{|c|c|c|}
\hline Item $^{1}$ & $\begin{array}{c}\text { Chinese } \\
\text { participants }\end{array}$ & $\begin{array}{c}\text { Australian } \\
\text { participants }\end{array}$ \\
\hline \multicolumn{3}{|c|}{ Short SL milk from China } \\
\hline Positive attributes & $1.2 \pm 1.2^{\mathrm{A}, \mathrm{X}}$ & $0.4 \pm 0.8^{\mathrm{A}}$ \\
\hline Negative attributes & $0.7 \pm 0.9$ & $1.3 \pm 1.0^{\mathrm{A}}$ \\
\hline \multicolumn{3}{|c|}{ Short SL milk from Australia } \\
\hline Positive attributes & $2.7 \pm 1.1^{\mathrm{B}, \mathrm{X}}$ & $2.7 \pm 1.1^{\mathrm{B}, \mathrm{X}}$ \\
\hline Negative attributes & $0.02 \pm 0.1$ & $0.3 \pm 0.6^{\mathrm{B}, \mathrm{X}}$ \\
\hline \multicolumn{3}{|c|}{ Long SL milk from China } \\
\hline Positive attributes & $0.6 \pm 0.9^{\mathrm{A}, \mathrm{Y}}$ & $0.3 \pm 0.7^{\mathrm{A}}$ \\
\hline Negative attributes & $1.2 \pm 1.1^{\mathrm{A}}$ & $1.4 \pm 1.2^{\mathrm{A}}$ \\
\hline \multicolumn{3}{|c|}{ Long SL milk from Australia } \\
\hline Positive attributes & $1.8 \pm 1.5^{\mathrm{B}, \mathrm{Y}}$ & $1.5 \pm 2.6^{\mathrm{B}, \mathrm{Y}}$ \\
\hline Negative attributes & $0.4 \pm 0.7^{\mathrm{B}}$ & $0.8 \pm 1.0^{\mathrm{B}, \mathrm{Y}}$ \\
\hline
\end{tabular}

${ }^{\mathrm{A}, \mathrm{B}}$ Significant difference between milk from China and Australia, $P<$ 0.001 .

${ }^{\mathrm{X}, \mathrm{Y}}$ Significant difference between short and long SL milk, $P<0.001$.

${ }^{1}$ Positive attributes $=1$ out of 4 attributes; negative attributes $=2$ out of 5 attributes (see Table 3 for attributes). 
Table 3. Attributes expected to be related to different short and long shelf life (SL) milks from China and Australia as measured with a 17-item attribute list, divided by Chinese and Australian participants

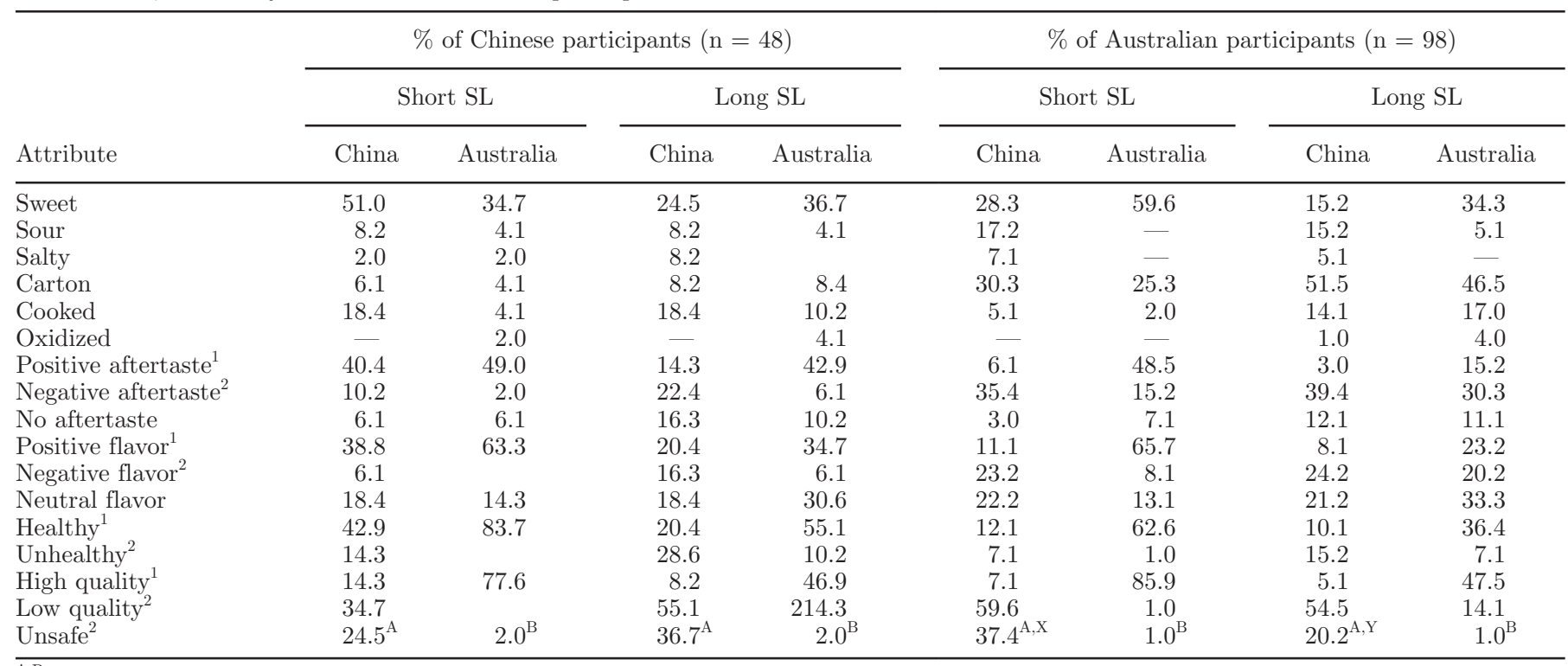

$\overline{\mathrm{A}, \mathrm{B}}$ Significant difference between Chinese and Australian milk $(P<0.05)$.

${ }^{\mathrm{X}, \mathrm{Y}}$ Significant difference between short SL and long SL milk from China $(P<0.001)$.

${ }^{1}$ Positive attributes.

${ }^{2}$ Negative attributes.

UHT milk by Chinese (International Market Bureau, 2012) and Australian consumers (Perkins and Deeth, 2001). However, a direct comparison between Chinese and Australian consumers was not carried out in previous studies. The skewed healthfulness perception may drive Chinese consumers to like and buy pasteurized milk. This might also explain why the majority of our Chinese participants reported mainly drinking pasteurized milk, whereas the majority of milk sold in China is UHT. Research in the area of functional foods suggests that consumers' willingness to buy functional foods correlates strongly with their beliefs that the food delivers the promised health benefits (Verbeke, 2005).

Milk is a common staple in Australia. Pasteurized milk is affordable (about $\mathrm{A} \$ 1.81 / \mathrm{L}$ branded, $\mathrm{A} \$ 1.01 / \mathrm{L}$ private label), widely available, and sold at a similar price as UHT milk (about A $\$ 1.61 / \mathrm{L}$ branded, $\mathrm{A} \$ 1.02 / \mathrm{L}$ private label; Dairy Australia, 2014). Expressed differently, $1 \mathrm{~L}$ of pasteurized milk is about $0.09 \%$ of the average Australian income per week per adult (Trading Economics, 2015a). It is estimated that Australians drink on average $105 \mathrm{~L}$ of milk per person per year, of which about $90 \%$ is pasteurized milk (Dairy Australia, 2014). Because of the repeated exposure to the taste of pasteurized milk, it is not surprising that the average Australian consumer prefers pasteurized over UHT milk. Similarly, it is not surprising that Chinese consumers prefer the taste of UHT over pasteurized milk. Repeated exposure has shown to be a powerful driver of consumer liking (Birch et al., 1987; Liem and De

Table 4. Types of milk, country of origin, and consumer endorsements that Chinese and Australian consumers expected to be related to goodtasting milk, high-quality milk, healthy milk, and safe milk

\begin{tabular}{|c|c|c|c|c|c|c|c|c|}
\hline \multirow[b]{2}{*}{ Item } & \multicolumn{4}{|c|}{$\%$ of Chinese participants $(\mathrm{n}=48)$} & \multicolumn{4}{|c|}{$\%$ of Australian participants $(\mathrm{n}=98)$} \\
\hline & $\begin{array}{l}\text { Good } \\
\text { tasting }\end{array}$ & $\begin{array}{l}\text { High } \\
\text { quality }\end{array}$ & Healthy & Safe & $\begin{array}{l}\text { Good } \\
\text { tasting }\end{array}$ & $\begin{array}{l}\text { High } \\
\text { quality }\end{array}$ & Healthy & Safe \\
\hline Short shelf-life milk & 85.7 & 91.8 & 93.9 & 61.2 & 81.8 & 81.8 & 78.8 & 60.6 \\
\hline Long shelf-life milk & 16.3 & $14.3^{\mathrm{A}}$ & $8.2^{\mathrm{A}}$ & 44.9 & 22.2 & $29.3^{\mathrm{B}}$ & $25.3^{\mathrm{B}}$ & 58.6 \\
\hline Produced in China & 8.2 & 6.1 & 46.1 & $12.2^{\mathrm{X}}$ & 2.0 & 4.0 & 9.1 & 5.1 \\
\hline Produced in Australia & 73.5 & 89.8 & 81.6 & $95.5^{\mathrm{Y}}$ & 88.9 & 88.9 & 80.8 & 90.9 \\
\hline
\end{tabular}

${ }^{\mathrm{A}, \mathrm{B}}$ Significant difference between Chinese and Australian participants $(P<0.05)$.

${ }^{\mathrm{X}, \mathrm{Y}}$ Significant difference between countries of origin $(P<0.001)$. 
Graaf, 2004; Cooke, 2007; Costa et al., 2014). Despite the large increase in milk consumption in China in the last decade, the average consumption of milk in China is low compared with that in Australia. In the period from 1996 to 2003, milk consumption of high-income earners increased by $300 \%$ but was still only about 18 L per person per year in China (Fuller et al., 2006). In 2008, the Chinese consumed about $22 \mathrm{~L} / \mathrm{yr}$ (Liu, 2008). Pasteurized Australian milk is considered a luxury food in China and too expensive for daily consumption for most Chinese. One liter of pasteurized Australian milk equates to about $4 \%$ of the average weekly income of an adult in China (Trading Economics, 2015b), making it about 44 times more expensive compared with pasteurized milk in Australia. Therefore, the attraction to pasteurized Australian milk could also be a result of the premium price of this product in China. In addition, for Chinese consumers, pasteurized Australian milk may represent the Western food culture, including its perceived safety (Qiao et al., 2010), and is therefore highly attractive for some (Wang et al., 2015), as shown by the data of the present study.

This study has some limitations that warrant attention. Our sample of Chinese consumers lived in Australia, and it is likely that they adjusted to some aspects of Australian food culture. Research in recent immigrants to the United States suggested that the most noticeable changes in eating habits occurred in those who had lived in the United States for more than 3 yr (Pan et al., 1999). Future studies should investigate a greater variety of Chinese consumers. The attributes "cooked" and "oxidized" may have been less understood by the Chinese participants as evidenced by the very few Chinese participants who used these attributes. Conclusions about these specific attributes can therefore not be made. Furthermore, we provided the participants with explicit information about the nature of the milk and country of origin. It is not known how this information would influence expectation and taste perception when it is placed on packaging, as in the natural environment.

In summary, this study showed cross-cultural differences in how consumers perceive UHT and pasteurized milks. Milk producers may alter packaging information to counteract negative expectations that consumers may have about UHT milk.

\section{ACKNOWLEDGMENTS}

We thank Nellie Thomson and Kathryn Collar (Centre for Advanced Sensory Science, Burwood, Australia) for their assistance during the data collection.

\section{REFERENCES}

Barraquio, V. L. 2014. Which milk is fresh? Int J. Dairy Sci. Process. $1: 1-6$.

Birch, L. L., L. McPhee, B. C. Shoba, E. Pirok, and L. Steinberg. 1987. What kind of exposure reduces children's food neophobia? Appetite 9:171-178.

Cooke, L. 2007. The importance of exposure for healthy eating in childhood: A review. J. Hum. Nutr. Diet. 20:294-301.

Costa, M. P., C. F. Balthazar, R. M. Franco, E. T. Marsico, A. G. Cruz, and C. A. Conte. 2014. Changes on expected taste perception of probiotic and conventional yogurts made from goat milk after rapidly repeated exposure. J. Dairy Sci. 97:2610-2618.

Dairy Australia. 2014. Australian dairy industry in focus 2014. Dairy Australia. Dairy Australia Limited, Southbank, VIC, Australia.

Dong, L., C. Bing, B. Jiankun, and L. Lin. 2015. Review and prospects of China's dairy industry trade in 2014. Chinese Dairy XX:47-79.

Dong, X., and Z. Li. 2015. Food safety issues in China: A case study of the dairy sector. J. Sci. Food Agric. http://dx.doi.org/10.1002/ jsfa. 710 .

Dunkley, W. L., and K. E. Stevenson. 1987. Ultra-high temperature processing and aseptic packaging of dairy products. J. Dairy Sci. 70:2192-2202.

Fuller, F., J. Huang, H. Ma, and S. Rozell. 2006. Got milk? The rapid rise of China's dairy sector and its future prospects. Food Policy $31: 201-215$.

Grunert, K. G. 2005. Food quality and safety: Consumer perception and demand. Eur. Rev. Agric. Econ. 32:369-391.

Hashim, L., and H. Chaveron. 1998. Comparison study of UHT milk aroma. Pages 393-400 in Food Flavors: Formation, Analysis and Packaging Influences. Proc. 9th Int. Flavor Conf.: The George Charalambous Memorial Symposium. Vol. 40. E. T. Contis, C.-T. Ho, C. J. Mussinan, T. H. Parliment, F. Shahidi, and A. M. Spanier, ed. Elsevier, Limnos, Greece.

Hongfeng, Z. 2011. Liquid milk market, consumer behaviour and market prospect. Industrial Economy 7:90-91.

Hough, G., L. Garitta, and R. Sanchez. 2004. Determination of consumer acceptance limits to sensory defects using survival analysis. Food Qual. Prefer. 15:729-734.

Huang, J. W. Y., Z. Yang, S. Rozelle, J. Fabiosa, and F. Dong. 2012 Marketing China's milk: A case study of the sales activity of dairy farmers in greater Beijing. China. Econ. Rev. 23:675-689.

International Market Bureau. 2012. The market for dairy products in China. Page 104 in the Minister of Agriculture and Agri.-Food Canada. Agriculture and Agri.-Food Canada, Ottawa, ON, Canada.

Keast, R. S. J., and J. J. Lau. 2006. Culture-specific variation in the flavor profile of soymilks. J. Food Sci. 71:S567-S572.

Liem, D. G., and C. De Graaf. 2004. Sweet and sour preferences in young children and adults: Role of repeated exposure. Physiol. Behav. 83:421-429.

Liem, D. G., F. Miremadi, E. H. Zandsra, and R. S. J. Keast. 2012a. Health labelling can influence taste perception and use of table salt for reduced-sodium products. Public Health Nutr. 15:2340-2347.

Liem, D. G., N. Toraman-Aydin, and E. H. Zandstra. 2012b. Effects of health labels on expected and actual taste perception of soup. Food Qual. Prefer. 25:192-197.

Liu, C.-G. 2008. China's Dairy Yearbook. China Agricultural Press, Beijing, China.

Meilgaard, M., G. V. Civille, and B. T. Carr. 1999. Sensory Evaluation Techniques. CRC Press, London, UK.

Pan, Y.-L., Z. Dixon, S. Himburg, and F. Huffman. 1999. Asian students change their eating patterns after living in the United States. J. Am. Diet. Assoc. 99:54-57.

Perkins, M. L., and H. C. Deeth. 2001. A survey of Australian consumers' attitudes towards UHT milk. Aust. J. Dairy Technol. 56:28-34.

Piqueras-Fiszman, B., and C. Spence. 2015. Sensory expectations based on product-extrinsic food cues: An interdisciplinary review of the empirical evidence and theoretical accounts. Food Qual. Prefer. 40:165-179. 
Plassmann, H., J. O'Doherty, B. Shiv, and A. Rangel. 2008. Marketing actions can modulate neural representations of experienced pleasantness. Proc. Natl. Acad. Sci. USA 105:1050-1054.

Qiao, G., T. Guo, and K. K. Klein. 2010. Melamine in Chinese milk products and consumer confidence. Appetite 55:190-195.

Singh, R. R. B., A. P. Ruhil, D. K. Jain, A. A. Patel, and G. R. Patil. 2009. Prediction of sensory quality of UHT milk-A comparison of kinetic and neural network approaches. J. Food Eng. 92:146-151.

Sumonsiri, N., and A. Barringer. 2014. Milk and ice cream processing. Pages 383-402 in Food Processing: Principles and Applications. 2nd ed. S. Clark, ed. Wiley-Blackwell, Hoboken, NJ.

Tang, V. C. M., A. T. Chetchik, and E. Cohen. 2015. Perception of wine labels by Hong Kong Chinese consumers. Wine Econ. Policy $4: 12-21$.

Tay, H. F. 2014. Australian dairy producers cash in on Chinese milk demand. Vol. 2015. ABC News. Accessed Jan. 6, 2016. http:// www.abc.net.au/news/2014-06-18/australian-dairy-producerscash-in-on-chinese-milk-demand/5533070.

Thomson, S. 2014. The Chinese are paying $\$ 8$ a litre for fresh Australian Milk. Business Insider Australia. May 22, 2014. Accessed Jan. 5, 2016. http://www.businessinsider.com.au/the-chinese-arepaying-8-litre-for-fresh-australian-milk-2014-5.

Trading Economics. 2015a. Australia Average Weekly Wages. Vol. 2015. A. Fedec, ed. Trading Economics, New York, NY.
Trading Economics. 2015b. China Average yearly wages. Vol. 2015. A. Fedec, ed. Trading Economics, New York.

Verbeke, W. 2005. Functional foods: Consumer willingness to compromise on taste for health. Food Qual. Prefer. 17:126-131.

Wang, O., H. De Steur, X. Gellynck, and W. Verbeke. 2015. Motives for consumer choice of traditional food and European food in mainland China. Appetite 87:143-151.

Wansink, B., and S. B. Park. 2002. Sensory suggestiveness and labelling: Do soy labels bias taste? J. Sens. Stud. 17:483-491.

Wansink, B., C. R. Payne, and J. North. 2007. Fine as North Dakota wine: Sensory expectations and the intake of companion foods. Physiol. Behav. 90:712-716.

Weston, S. 2014. Over $60 \%$ of milk consumed in China is UHT, says new report. Accessed Jan. 6, 2016. http://www.foodbev.com/ news/over-60-of-milk-consumed-in-china-is-uht/.

Williamson, P. O., J. Robichaud, and I. L. Francis. 2012. Comparison of Chinese and Australian consumers' liking responses for red wines. Aust. J. Grape Wine Res. 18:256-267.

Xiu, C., and K. K. Klein. 2010. Melamine in milk products in China: Examining the factors that led to deliberate use of the contaminant. Food Policy 35:463-470.

Zabbia, A., E. M. Buys, and H. L. De Kock. 2012. Undesirable sulphur and carbonyl flavor compounds in UHT milk: A review. Crit. Rev. Food Sci. Nutr. 52:21-30. 